\title{
RFID Isn't Science Fiction
}

$\mathbf{F}$ or those of you who read my editor's note last month, you'll recall I'm throwing this space open for comment: What should the editor's note page be used for? Orienting you to the issue you're about to read, highlighting some of the sights to see? Should I give some context as to how our Editorial Advisory Board grappled with the topic of the month's special report? Or should we do away with the editor's note altogether?

I've already received the first of your responses with some interesting suggestions. As promised, I'll share some of the responses in an upcoming issue-and if you have any thoughts on how best to use this space, let me know!

In the meantime, there are some things in this month's ACM Queue worth pointing out. I'll stay away from calling them "new" and "exciting," as those descriptors are probably the kiss of death to most readers (<flame retardant $>$ right up there with calling a software product a "solution"-yes, you know who you are out there! $</$ flame retardant $>$ ). OK, so here goes:

New and exciting item 1: (I know I just said I wouldn't use those descriptors, but I can't help myself.) This month's special report is on RFID, but you've seen the cover, so you already know that. What you don't know is that when the board sat down to brainstorm this issue, we asked Intel Research principal engineer Roy Want to come by and help us think through the issues. One thing that became immediately clear is that RFID is a technology with both a present and a future-there are lots of wonderful ways RFID will be used in the future, and there are some very important ways RFID is being used now.

Finding the line between the really-will-be-here-soon present (6- to 18-month horizon) and the promising-butnot-here-yet future proved harder than one might think. And we felt finding that line of separation was important-after all, there is a lot of RFID that is in no way science fiction. It's here now (which may include being with vendors but not yet in your shop) and it's affecting vast amounts of commerce and technology in the States and abroad (you've all heard about Wal-Mart and the military RFID mandates, I'm sure).

And yes, there's some even cooler stuff that's a few years out-but sticking to Queue's mission, we felt it was

\section{Is RFID going \\ TO WREAK ITS HAVOC \\ ON YOUR SYSTEMS?}

that's likely to be disruptive.

Our first piece is from Roy Want himself and is just the sort of orienting overview one needs to get a handle on the key issues. Just how do these little tags work anyhow? Want has been a leader in RFID research, and we're delighted to have his overview ("The Magic of RFID") in this issue. Of course once you understand a little bit about how RFID technology works, the next question is "So how is it relevant to me?" Our next piece, "Integrating RFID," explores just that question: How is RFID likely (or not likely) to play a role in your organization, and what are the problem areas to be on the lookout for? Author Sanjay Sarma, MIT Auto-ID Center cofounder, guides us through the questions.

New and exciting item 2: (Oops, I did it again.) Often our monthly interview is tied into the topic of our special report. Not this month. "Why?" you ask. Well, if you had a chance to sit down with the person responsible for the Mars rover operating system port, would you jump on it? We did (have the chance) and we did (jump on it). This month's interview: Mike Deliman, currently of NASA's JPL (Jet Propulsion Laboratory), and formerly of Wind River. Talk about reliability reqs in remote locations.

New and exciting item 3: (Is this device played out?) This item really is new-Queue has decided to take its own spin on Ms. Manners, and so we've started a new, regular department. Meet Kode Vicious. He'll be with us every month to answer your letters, so if you've got a koding question or a krazy ko-worker, drop him a line.

OK, I'm done. Enjoy! Q

EDWARD GROSSMAN is responsible for Queue, so blame him if you don't like it: edgrossman@acmqueue.com. In earlier incarnations he was a development project manager at a still-in-business dot-com and a closet coder (his parents still don't know_-"Our son Ed? Oy, he works with computers, doing something"). 